\title{
The Impact of Community Care Service System on the Quality Life of the Elderly
}

\author{
Jinbin Hao ${ }^{1}$, Jiangpeng Zhang ${ }^{1}$ \\ ${ }^{1}$ School of Economics and Management, Inner Mongolia university of Science and Technology,Baotou \\ street 7,China \\ Qenpenbian@163.com, 14442746@qq.com
}

Keywords: Community endowment, Quality of life, Influence, Community service system

\begin{abstract}
Compared with institutional pension and home-based care, community care system has an obvious advantage in the psychological cognition and service acceptance of the elderly. Based on the system theory, the effect of community care service system on the quality of life of the elderly is analysed empirically. The study found that community infrastructure, community life care services, community self-governing services, and medical care services were positively correlated with the quality of life in the elderly. In this paper, the corresponding countermeasures are put forward.
\end{abstract}

\section{Introduction}

Since China's begins to be involved in the" aging society” in 1999, the old age population has been growing faster. In 2014, the proportion of senior citizens in the elderly population reached $15.5 \%$, indicating that China actually entered an aging society(Silverstein,2015). Social pension pressure is increasing. The construction speed of this socialized old-age service is constantly improving. The government proposed and promoted the three ways for old-age care: home-based care, institutional pension and community care. In terms of structural care, the number of beds reached 6.13 million by the end of 2014 , with an average of 4.49 beds per 1,000 , nearly twice as many as 1.8 million in 2005. But the potential for a third of the population to grow by 2050 is still not enough to meet the growing demand for institutions. In the home, the family pension is weakened by the impact of the small change of family structure, which often fails to realize the normal operation of the elderly (Ramon S, 2016). The natural advantage of community endowment has led to the rapid advancement of community care system model.

The influence of community care system service model on the elderly mainly includes: (1) community endowment makes up for the deficiency of family endowment (Zimmer, 2003). Traditional family pension mode, in what is now the family more and more tend to be miniaturization and core, the empty nest rate is higher and higher, unable to meet the living requirement and the improvement of life quality of old people, the psychology of the elderly and the negative impact on the quality of life as well, community endowment patterns to meet the various needs of the elderly life, make up for the deficiency of the traditional family endowment, many scholars to the community endowment the influence of the quality of life of the elderly are studied, and the continuous summary, make up the shortages of the traditional pension at the same time also promote the progress of the community endowment service mode. (2) the mode of community care system service is more in line with the thinking cognition of the elderly. From the community care system model, it can be found that this model can improve the quality of life and the warmth of the elderly. Older people are more likely to spend more time with their families than in nursing homes. The "home + community" old-age pension model makes the elderly feel rich in their spare time, and the elderly can get along with their families more(Feldman,2004). 


\section{The factors that influence the quality of life of elderly people based on system theory}

\subsection{System theory and its application}

The community care system service system is carried out on the basis of government subject, community care system institution and community elderly subject. The development of system science has been applied to the solution of specific problems in various disciplines and fields. System science says that everything can be thought of as an orderly system. The elements that can be separated from the inside can be integrated into the structure of the interaction between the elements and the interaction between the elements. The system structure is an evolution process from order to disorder to order. The orderly structure of the system is generally expressed as the division of the internal subsystems, the system elements are frequently interacting with each other, and as an overall output efficiency is higher. The disordered structure of the system is the inevitable state of the system development process. After operation, the system constantly breaks its equilibrium state transition to unbalanced state, resulting in the emergence of the system disordered structure. The process of system development is to transform between continuous order and disorder, thus promoting the constant change of things.

At the same time, as shown in figure 1.1, the operation of the system needs to be supported in a certain environment. Environment to provide the basic resources for the system, the system to get input from the environment constantly, the input can be a person accused of can also be controlled and between system and environment resources are actively seek passive input. After obtaining input resources, the system transforms and processes the resource according to its own structure and function, and outputs it to the environment after the transformation. In the social economic system, the system actively obtains the resources from the outside world according to its own needs, on the other hand, the passive acceptance of the external environment changes. The economic system then processes the resources according to its own way of operation, and constantly adjusts its behaviour to adapt to the environment and the environment, so as to realize the mutual evolution of the external environment and the system itself.

For community care system services, the operation of the system is carried out in the interaction between government departments, community care system institutions and the elderly. The external environment constantly inputs resources to the system, mainly through the pension policy, the allocation of pension resources and the social service force to enter the community. The ultimate effect of community care system will depend on the fit between external resources and the needs of the elderly community. In particular, the services provided by community care system can be corresponding to the system elements of the improvement of the quality of life of the elderly.

\subsection{System factors that affect the quality of life of the elderly}

(1)Physical health factors. A healthy body is a guarantee of good life, without a healthy body, the life of the elderly will be greatly affected (Miller, 1991). Among the diseases that affect the health of the elderly, the most important are chronic diseases and major diseases such as disability and life. According to the statistics, says chronic diseases are important influential factors of the elderly health, there are more than $70 \%$ of the elderly with chronic disease, the old man at least have high blood pressure, diabetes, hyperlipidaemia, coronary heart disease, stroke, and respiratory disease that one of the 6 kinds of common chronic diseases. Therefore, in daily life, the elderly are always concerned about their physical condition, regular physical examinations and preventive and timely treatment of various chronic diseases. In addition, old people should exercise regularly, pay attention to their physical health, and improve their physical quality through exercise.

Therefore, the health care service and the provision of physical exercise facilities should be paid attention to the quality of life of the elderly. Perfect health care service system to improve the level of medical service in community endowment, keep track of the old people's physical health, active prevention and treatment for the old. Sound exercise facilities provide for the elderly in the case of positive for disease treatment, reasonable physical training, provide supplementary role for medical services, which have positive effect on the health of old people.

(2)The enrich factor of the amateur life. Another important factor affecting the quality of life of the elderly is the lack of leisure. In the old age, life cannot be equated with physical exercise and 
physical health. It should also include a rich cultural life and keep your body and mind in good condition. Their amateur life, activities like practicing sword, singing, playing chess and visit the museum, art museum, science museum and other places of activity is greatly enrich the spare life of the elderly, to improve the elderly life of comfort and satisfaction. Old people is a kind of vulnerable groups in society, especially in an aging population growing today, it is necessary for the elderly living conditions for further understanding, and increase the spare life of old people. The centres can set up chess and card room, reading room, free activity room, etc., also can set up certain activity places according to interests. Be responsible, open and clean regularly. In order to get the elderly to better participate in it, we can make certain rules and regulations to prohibit the occurrence of uncivilized behaviors; It can also carry out certain activities and enrich the leisure life of the elderly. Old people take part in the activity of interest, exchange old people's idea, old people can also according to their liking, undertake singing, dance, still can hold dance class and so on.

(3)Psychological fluctuation factor. Most people will go into old age and after departure, headturning going on in the life time structure, discomfort, mental ideas, many old people still want to do something with no chance. Some elderly people are depressed because they are out of social life and have no communication. There are some old people because they cannot face the condition of the old age and death, surrounded by friends and relatives for fear of the drag on death, these ideas have certain pressure on the elderly spiritual (Chen Youhua, 2014). Old people after entering in later life, on the physical, psychological and life will have different idea, let the old people in a positive state of mind to face life is responsible for the old psychological, is also responsible for the elderly family members. Therefore, good psychological counselling can help the elderly to cope with life positively and improve their quality of life.

(4)Good life care service factor. Improving the quality of life of the elderly is not only in the provision of external facilities, but also a large proportion of good life care services. Life care services include: three meals a day, a clean, open telephone hotline for door-to-door services, the provision of living and medical care for an elderly person who cannot care for himself, and so on. For an older person, daily care is required, both mentally and physically, as the age increases in physical health. Due to the implementation of the one-child policy, the influence of long-term work outside or children, encourage their life is confined to the family's inner circle, especially the part of the old man life cannot provide for oneself, need community care services. If increasing community understanding of the old man's physical and psychological needs, regularly on the door for the elderly life care, sanitary and other services, will be more conducive to promote the quality of life of the elderly.

\section{The impact of community care system service on quality of life of the elderly and its empirical evidence}

\subsection{Assumptions about the impact of community care system services on the elderly quality of life}

According to Maslow's theory of demand, understanding the needs of daily life of the elderly and analysing the factors that affect the quality of life of the elderly. From the level of demand, these old people are satisfied with basic physiological needs for the elderly who cannot care for themselves. For the elderly who live alone, the pursuit of emotional and belonging needs; For the elderly who have just retired and feel like they are doing nothing, the need for self-fulfilment. Therefore, according to the service provided by the community care system model, the following assumptions are made for the satisfaction of the actual needs of the elderly:

It is assumed that the improvement of community infrastructure will improve the quality of life of the elderly

The study of scholars shows that the quality of life of senior citizens in China is higher than that of rural seniors (he quan, 2015). Due to the rapid development of urban rural economy, the provision of living facilities and public services is higher than rural areas, and the quality of life of elderly people is relatively high. But in the process of urban-rural integration, countries continue to intensify construction of rural communities, rural communities and urban communities, the elderly's 
easy to have a healthy body discomfort, the status of the disabled. The community should establish better community facilities for these situations, such as the provision of certain physical exercise facilities for the elderly to exercise basic living exercises. After retirement, the elderly need more recreational activities to enrich their lives, and the community needs to provide the perfect activity facilities. Old people's health, is an important aspect of community nursing service, the community should as far as possible to provide perfect medical service facilities, please professional expert of aged care services, for regular inspection and monitoring of the old people's body, etc.

It is assumed that the improvement of community life care services will improve the quality of life of the elderly

Life care service is one of the important factors affecting the quality of life in the elderly, mainly includes three meals a day, health, clean and give the place of the elderly care for their children during the day not at home, set up the community elderly telephone service hotline for on-site service or door-to-door reservation service. Community in life care services, should hire professional nursing staff, should hold health card mount guard, in addition to the old man's three meals a day care, health, clean, also should consider to the old people's physical health situation, timely monitoring and prevention. In addition, the psychological health of old people is also a not allow to ignore, through investigation and study, found that accept to take care of the management service of the elderly living in the home, through a series of life care, both physical and psychological aspect, the elderly and take care of people's satisfaction and life have very big improvement (Albert, 2013). Only taking care of the daily life of the elderly, physical health and mental health will improve the quality of life of the elderly.

It is assumed that the improvement of community self-government management services will improve the quality of life of the elderly

When some old people retire, they cannot adapt to the changes in life, and the changes in their psychological emotions will lead to a decline in quality of life. Therefore, community endowment in the daily life of old people at the same time, the elderly should be paid attention to psychological changes, and in addition to the positive psychological guidance, to a certain extent, some of the elderly for the elderly in the community can participate in community affairs management and activities are also necessary. In the elderly produce psychological gap, can actively play the "heat" of old people, such as the elderly organize activities of some of the "fire alarm" propaganda, or small "celebration of National Day" of similar activities, let the elderly actively involved, not only easy to improve the well-being of the elderly, is more advantageous to improve the elderly's interest, as well as to reduce the burden of the community staff; On the other hand, elderly people can participate in mediation work, such as regulating neighbourhood disputes. The elderly more rich social experience and sociable way experience more rich, let the elderly to participate in such adjustment, is advantageous to the construction of harmonious community at the same time also help the elderly self-responsibility. Therefore, for the elderly to live in later life, some things can be done to achieve the inner enrichment of the elderly, thus to improve the quality of life.

Hypothesis 4 good medical care services can improve the quality of life of the elderly

The impact of the analysis on the quality of life of the elderly is analysed from two aspects: the facilities and personnel of community medical care services. From the perspective of facilities, the basic health service centres in the community provide protection for the daily chronic diseases of the elderly. Good health service centres should include perfect medical service facilities, in addition to monitoring instrument equipped with basic, basic rehabilitation training facilities can also help the elderly health of body and elderly postoperative rehabilitation. In terms of personnel, community health service centres should also pay attention to the mental health of the elderly. So should hire professional elderly diseases for the elderly health monitoring and inspection, and shall be equipped with professional psychological consultants to channel the mental health of old people.

\subsection{Questionnaire and empirical analysis results}

Adopt the method of stratified random sampling questionnaires and field interviews, finally choose sample plot, a total of seven, the questionnaire of the actual number is 220, excluding the wrong answer or answer after the actual use of 195 valid questionnaires. The questionnaire mainly 
measures the satisfaction of various services and USES Likert 5 point scale to measure.

The gender aspect of the questionnaire was slightly higher than that of women, accounting for $55.9 \%$ of the total. In terms of educational background, middle school education accounted for $55.4 \%$, 35.9\% in high school and secondary school, and $8.7 \%$ in college and above. In terms of living conditions, $55.4 \%$ of people said they lived with their spouses but did not live with their children. In terms of income, the majority of elderly people depend on their pension to live, accounting for $71.8 \%$, followed by spouse or children's income, accounting for $9.7 \%$, government assistance and labour income, respectively $7.2 \%$ and $7.7 \%$ respectively. In terms of health, 79.5 per cent of the elderly said they were well, and 16.4 per cent of the elderly had chronic illnesses or major surgery, and 4.1 per cent said they needed care.

Table 1 descriptive analysis of overall and well-being of community management

\begin{tabular}{cccccc}
\hline & N & Min & Max & Mean & $\begin{array}{c}\text { Standard } \\
\text { deviation }\end{array}$ \\
\hline $\begin{array}{c}\text { Facilities number } \\
\text { Time for medical }\end{array}$ & 195 & 1 & 5 & 2.989 & 0.792 \\
$\begin{array}{c}\text { care } \\
\text { Time for day care }\end{array}$ & 195 & 1 & 5 & 3.189 & 0.792 \\
$\begin{array}{c}\text { number of platform } \\
\text { services }\end{array}$ & 195 & 1 & 5 & 3.564 & 0.546 \\
\hline
\end{tabular}

From table 1, we can see that in the community to provide again obtain employment service platform of The Times, the highest satisfaction of old people, in the community to provide facilities for senior citizens, the old people satisfaction. Terms of the number in the community to provide infrastructure, most satisfied with the elderly, and the results are basically consistent, in terms of basic living facilities, the community to provide comprehensive infrastructure, meet the needs of the elderly life. In terms of the number of community again obtain employment service platform, overall, old people of the community generally again obtain employment service content is satisfactory, but there are also job content of the single, individual staff service attitude and ability is insufficient. Old man satisfaction is higher, and day care services of most of the community to provide services mainly have children not at home during the day to provide door-to-door service for the old man, to help the old man cleaning and cooking, etc., to take care of every aspect of daily life. It is worth noting, however, that the community is missing in the provision of voluntary services during the survey visit. On the other hand, the majority of elderly people are not older than 80, and relatively few are in need of special care. In terms of medical care provided by the community, many elderly people say that most of the community is equipped with basic medical conditions, such as health service clinics, community hospitals and so on. The basic medical facilities provided by the community facilitate the monitoring of the elderly's physical health and facilitate the diagnosis and treatment of the elderly at any time, so as not to delay the optimal treatment time.

Table 2 analysis of the services provided by the community

\begin{tabular}{|c|c|c|c|c|}
\hline & Facilities number & Medical care Time & Day care Time & $\begin{array}{c}\text { platform services } \\
\text { number }\end{array}$ \\
\hline Facilities number & 1 & & & \\
\hline Medical care Time & $.413^{* *}$ & 1 & & \\
\hline Day care Time & $.335^{* *}$ & $.477 * *$ & 1 & \\
\hline $\begin{array}{c}\text { platform services } \\
\text { number }\end{array}$ & $.302 * *$ & $.468 * *$ & $.574 * *$ & 1 \\
\hline
\end{tabular}


The correlation results of table 2 shows that the number of community to provide facilities for senior citizens and community health care service, day care service time and again obtain employment service platform of the number of simple correlation coefficient of $0.413,0.335,0.302$, respectively. The probability of their correlation coefficients is approximately 0 . Therefore, the null hypothesis can be rejected when the significance level alpha is 0.01 . According to the analysis of the correlation coefficient in the conclusion, in all aspects of the community management, community facilities for senior citizens and the medical care service time, the number of day care service time and again obtain employment service platform has certain correlation between the number of ways.

In order to further explain all of the services of community management provides satisfaction for the elderly, the influence of the number of elderly activity facilities provided in community, medical care service, day care services with the time, the number of again obtain employment service platform for the independent variable, the elderly satisfaction as dependent variable using linear regression analysis, and according to the analysis of regression analysis results of the community to provide services for the elderly life quality. The linear regression equation is established as follows:

$$
\mathrm{Yn}=\beta+\beta 1 \mathrm{X}+\beta 2 \mathrm{X} 2+\ldots \ldots+\beta 4 \mathrm{X} 4
$$

Yn is among them old people life quality, the $\mathrm{X} 1, \mathrm{X} 2, \mathrm{X} 3, \mathrm{X} 4$, represent the dependent variable community to provide facilities for senior citizens, medical care service time, the number of day care service time, again obtain employment platform service times, 1 - beta 4 as coefficient of beta.

The calculation shows that the adjustment of $\mathrm{R}$ squared is 0.779 , indicating that the explanatory power of the model is better. The fit of the model test, when the regression equation containing different independent variables, $\mathrm{F}$ value is 36.757 , its significant probability value is 0.000 , less than 0.01, the results showed that the final regression equation fitting effect is very good. From table 3 shows that the number of facilities for senior citizens, medical care service, day care services with the time, and again obtain employment service of the number of the corresponding $t$ value were 3.799, 1.982, 3.411, 1.982, and the corresponding p values were less than 0.05 have significant statistical significance. According to table 3, the coefficients of each independent variable are 0.388, $0.086,0.292$ and 0.282 respectively. In equation (1.1), we know, the number of facilities for senior citizens, medical care service, day care service time and again obtain employment service platform the influence of the number of times the quality of life for the elderly were positively correlated. The activity facilities provided by the community have the greatest impact and the medical service has the least influence. This may be related to the fact that nearly 80 per cent of elderly people have a good sense of self-care.

Table 3 results of linear regression analysis of elderly satisfaction

\begin{tabular}{cccccc}
\hline model & \multicolumn{2}{c}{ Nonstandardized coefficient } & The standard & S \\
& $\mathrm{B}$ & Standard error & & $\mathrm{T}$ & Sig. \\
\hline (constant) & 0.621 & 0.213 & & 2.915 & 0.004 \\
Facilities number & 0.378 & 0.099 & 0.388 & 3.799 & 0.000 \\
Medical care Time & 0.084 & 0.086 & 0.086 & 1.982 & 0.02 \\
Day care Time & 0.296 & 0.087 & 0.292 & 3.411 & 0.001 \\
platform services & 0.243 & 0.083 & 0.282 & 2.941 & 0.012 \\
number & & &
\end{tabular}

\section{Conclusions}

Under the guidance of system theory, through empirical analysis, four dimensions of the community endowment service found that the number of facilities for senior citizens, medical care service, day care service time and again obtain employment service times are associated with a significant quality of life for the elderly. The effective operation of the community care system 
service system promotes the improvement of the quality of life of the elderly. However, community care system service is a new kind of pension model in China, which still needs to be explored.

The future should continue from establishing and perfecting the laws and regulations and standard, guide the development of community endowment service, establish a community service centre, implementation management, professional talent and services, to further improve the infrastructure, to distinguish the categories of the community, the implementation of life care services continue to promote the construction of community endowment etc., in order to better cope with the challenges of an aging society.

\section{Acknowledgements}

Humanities and social science fund project (Number: 15yjczh230); The Inner Mongolia social sciences planning project (Number: 2015jdb029), Innovation fund projects funded in Inner Mongolia university of science and technology (number: 2012ncl045); University student science and technology innovation fund project (Number: 2015069).

\section{References}

[1] Baijie, 2016.A brief discussion on China community care system service [J]. Fujian quality management,(05): pp.60-68.

[2] Chen youhua, wukai, 2014. Planning and design of community care system service - taking nanjing city as an example [J]. Population journal,(01): pp.42-48.

[3] Cong, Z., \& Silverstein, M,2015. Intergenerational Support and Depression Among Elders in Rural China: Do Daughters-In-Law Matter?. Journal of Marriage and Family, 70(3), pp. 599-612.

[4] Feldman, M. W., \& Jin, X,2004. Children, marriage form, and family support for the elderly in contemporary rural China: the case of Songzi. Research on Aging, 26(3), pp.352-384.

[5] Entwisle, B., Henderson, G. E., Short, S. E., Bouma, J., \& Fengying, Z,1995. Gender and family businesses in rural China. American Sociological Review, pp. 36-57.

[6] Fennell,G.,Phillipson,C,Wenger,C.The process of aging:socialaspects,in Elderly People in the Community:Their Service Needs,London,HMSO,1998.

[7] Giles, J., \& Mu, R,2007. Elderly parent health and the migration decisions of adult children: Evidence from rural China. Demography, 44(2), pp.265-288.

[8] Miller, B., McFall, S., \& Montgomery, A,1991. The impact of elder health, caregiver involvement, and global stress on two dimensions of caregiver burden. Journal of Gerontology, 46(1), pp.S9-S19.

[9] Ramon S. Beyond community care: Normalization and integration work[M]. Springer, 2016.

[10] Zimmer, Z., \& Kwong, J,2003. Family size and support of older adults in urban and rural China: Current effects and future implications. Demography, 40(1), pp. 23-44. 